\title{
O desenvolvimento de motores a álcool e bicombustível: concentração territorial e risco de perda das vantagens de first commer ${ }^{\dagger}$
}

\author{
Luiz Fernando Rigacci Vazzolér* \\ Maria Beatriz Machado Bonacelli** \\ Ana Maria Carneiro***
}

Resumo: Apresenta-se neste artigo uma análise do quadro técnico-científico da produção do conhecimento relacionado ao desenvolvimento dos motores a álcool e bicombustível (flex) no Brasil no período que se estende entre 1975 e 2008, a partir de indicadores de produção científica e de produção técnica. Os principais resultados indicam baixos números absolutos de publicações e de patentes, e também de colaborações e cooperação entre os principais atores envolvidos nestas atividades. Esta constatação traz grande preocupação, pois os resultados estão atrelados a áreas do conhecimento (ciências agrárias, biologia, química, entre outras), a setores da atividade econômica (agroindústria da cana-de-açúcar e do etanol e indústria automobilística) e a um estado da federação (São Paulo) de grande relevância para o cenário econômico, social, de C\&T e inovação nacional, indicando a necessidade de política pública de maior envergadura para não apenas dar dinamismo científico a essas iniciativas, mas também melhores resultados técnico-econômicos, para o Brasil não perder as vantagens de ser first commer nesta área.

Palavras-chave: P\&D agrícola; Redes de colaboração; Patente.

Classificação JEL: Q16; L14; O34.

\footnotetext{
$\lceil$ Este trabalho faz parte do projeto temático Fapesp "Desenho organizacional do programa BIOEN: propriedade intelectual".

* Graduado em Geografia pela Universidade Estadual de Campinas (Unicamp). Mestrando em Política Científica e Tecnológica na Unicamp e pesquisador do Grupo de Estudos sobre a Organização da Pesquisa e da Inovação (GEOPI/ Unicamp). Endereço eletrônico: luiz.vazzoler@ige.unicamp.br.

** Doutora em Ciências Econômicas pela Université Toulose (França). Professora adjunta do Departamento de Política Científica e Tecnológica (DPCT/IG) e Pesquisadora do GEOPI/DPCT pela Universidade Estadual de Campinas (Unicamp). Endereço eletrônico: bia@ige.unicamp.br.

*** Doutora em Política Científica e Tecnológica pela Universidade Estadual de Campinas (Unicamp). Pesquisadora do Núcleo de Estudos de Políticas Públicas da Unicamp e do GEOPI. Endereço eletrônico: anamaria@nepp.unicamp.br.
} 


\section{Introdução}

O Programa Nacional do Álcool (Proálcool ou PNA) surgiu em 1975, como resposta à crise do petróleo de 1973 e a consequente alta internacional nos preços do barril do óleo. Mas a produção de etanol no Brasil entre 1970 e 2007 possui dois grandes marcos: o primeiro no ano de 1979, quando da introdução dos automóveis movidos exclusivamente a álcool - em quatro anos a produção de veículos a gasolina é superada pelo movido a álcool, com ápice em 1986, quando uma crise de abastecimento de etanol dá início ao declínio da produção; o segundo marco é o ano de 2003, que representa o início da utilização dos veículos flexíveis (flex ou bicombustíveis) - cerca de dois anos após a introdução no mercado, a produção superou a dos carros a gasolina e atualmente este tipo de veículo domina mais de $80 \%$ do mercado, resultando num grande estímulo à produção e expansão da cultura canavieira no país.

Tendo esse pano de fundo, o artigo analisa os indicadores da produção científica e da tecnológica, além dos indicadores de colaboração no Brasil, relacionados ao desenvolvimento dos motores a álcool e bicombustível (flex) no período que se estende entre 1975 e 2008, procurando mapear os esforços tecnológicos envolvidos no período.

Além desta introdução, este texto é desenvolvido pela descrição da metodologia baseada em instrumentos de monitoramento tecnológico para apoio a políticas e estratégias voltadas a atividades de P\&D e inovação, em que a construção de indicadores é o elemento central do processo (Silva; Zackiewicks; Bonacelli, 2005) e apresenta os principais resultados da pesquisa realizada relativa à produção científica, tecnológica e de colaboração no tema em questão, seguidos pelas considerações finais e a bibliografia.

\section{Nem produção científica, nem produção tecnológica - como não perder a liderança no cenário mundial?}

A partir da análise do contexto da produção e utilização do álcool combustível no Brasil relacionado ao desenvolvimento de motores automotivos e do método de prospecção tecnológica, ferramenta desenvolvida desde a década de 70 com vistas a acompanhar o progresso de uma dada tecnologia para reagir de forma ponderada no tempo futuro, via consideração de possibilidades alternativas e uma síntese do progresso e suas implicações, foi possível a seleção de palavras-chave que permitiram o levantamento e as buscas da produção científica e tecnológica relativas a motores automotivos no Brasil. As bases de dados referenciadas consultadas foram ISI - Web of Knowledge e Scielo para artigos; e a base de patentes do Instituto Nacional de Propriedade Industrial 
(INPI). Posteriormente, foram observadas as instituições técnico-científicas envolvidas neste processo, sua localização geográfica e a colaboração em redes de pesquisa. O recorte temporal utilizado nas buscas inicia-se em 1975 e vai até 2009 para artigos e para 2008 patentes. As principais palavras-chave para artigos foram: álcool combustível, etanol combustível e biofuel; para patentes foram: "controle and combustível", "sistema and injeção and combustível" e "gasolina and álcool”. Seguem as análises.

Nas consultas feitas à base ISI foram encontrados 928 artigos (excluídas as repetições), dos quais 88 têm autoria e/ou coautoria de pesquisadores em instituições localizadas no Brasil. Os países que contam com maior número de publicações são Estados Unidos, Brasil, China, Canadá e Japão, nesta ordem. Um olhar mais atento sobre as publicações com autores brasileiros revela que as instituições que mais publicam estão localizadas no estado de São Paulo; são elas as universidades estaduais paulistas: Unesp, USP e Unicamp. Notase uma ênfase no número de publicações a partir dos anos 2000, período que corresponde à introdução do carro no mercado nacional e também o período de maior cobertura da base, como ilustrado no Gráfico 1, a seguir.

Gráfico 1 - Número de publicações de instituições brasileiras por ano no tema

"veículos a álcool e bicombustíveis" na base ISI - Web of Knowledge, 1975-2009

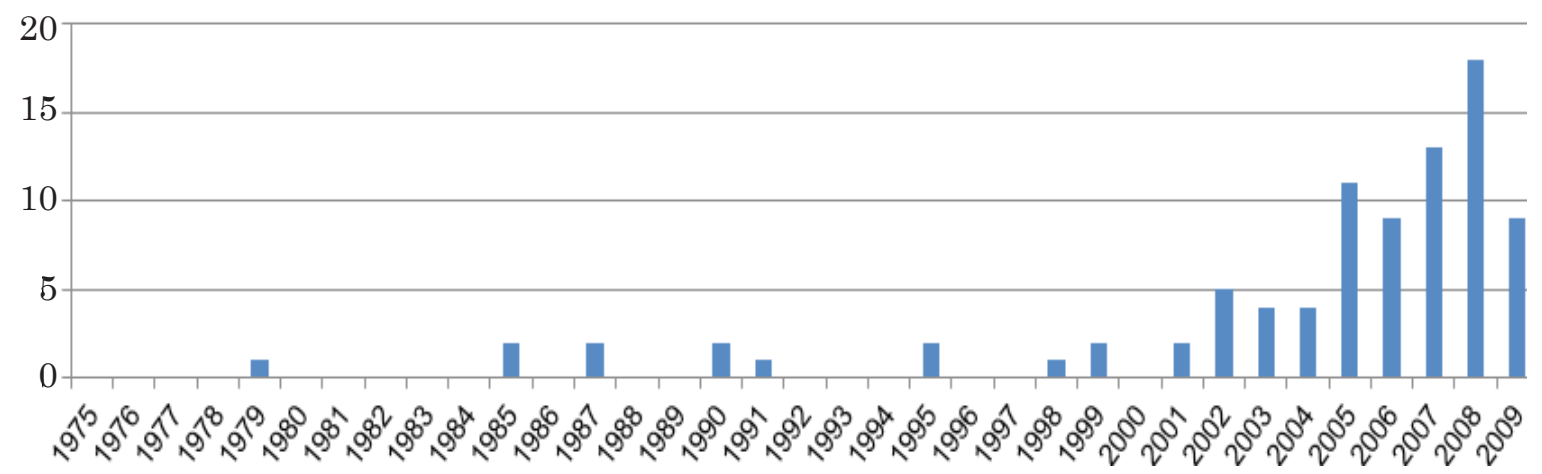

Fonte: Consulta à base ISI - Web of Knowledge (2010).

As publicações encontradas na base Scielo apresentam um número mais restrito - o total encontrado, sem repetição, foi de 35 artigos -, um indicativo de que os artigos mais antigos das revistas nacionais não devem estar inseridos nessa base de referências, como apresentado acima. Ao se observar aqueles artigos que contêm ao menos um coautor brasileiro, este número diminui para 29 publicações, todas elas em periódicos editados em território nacional. Os dados obtidos a partir das buscas apresentaram 17 instituições diferentes, sendo 15 nacionais e duas internacionais (Faculdade de Ciências do Porto e Universidade Politécnica de Torino, coautoria com Unesp e UEM, respectivamente). USP e Unesp são as que mais publicaram - cada uma delas com 7 artigos publicados.

A distribuição temporal é bastante semelhante aos artigos referenciados 
pela base ISI, com concentração a partir dos anos 2000. Ao olhar a área do conhecimento dessas publicações, de acordo com os periódicos, o destaque é a Química, sobretudo artigos que tratam sobre análise e determinação de propriedades específicas do álcool etílico.

Já a forma escolhida para realizar a medição das tecnologias relacionadas com o desenvolvimento dos motores a álcool e flex fuel foi o número de pedidos de patente, seja ele de invenção, modelo de utilidade ou certificado de adição, depositadas junto ao INPI. O resultado por tipo de proteção mostra a maior frequência de patentes de invenção, que representam mais de $90 \%$ da base montada. As buscas realizadas nas bases do INPI alcançaram 525 pedidos, sendo 246 pedidos arquivados, 137 depósitos ainda em análise e 142 cartas patente expedidas. Destas últimas, 89 são patentes extintas e 53 patentes em vigência. Este elevado número de cartas patentes, em relação ao universo de pedidos em análise, indica a maturidade tecnológica da temática em estudo.

O aumento no número de pedidos de patente próximo ao advento do carro a álcool, entre 1979 e 1982, e próximo ao lançamento do automóvel bicombustível, com uma discreta alta em 2001 e um aumento nos pedidos posteriores à introdução dos veículos flex no mercado, com pico no ano de 2004 podem ser observados no Gráfico 2, abaixo.

Gráfico 2 - Pedidos de patente no tema veículos a álcool e flex depositados por ano no INPI, 1975-2008

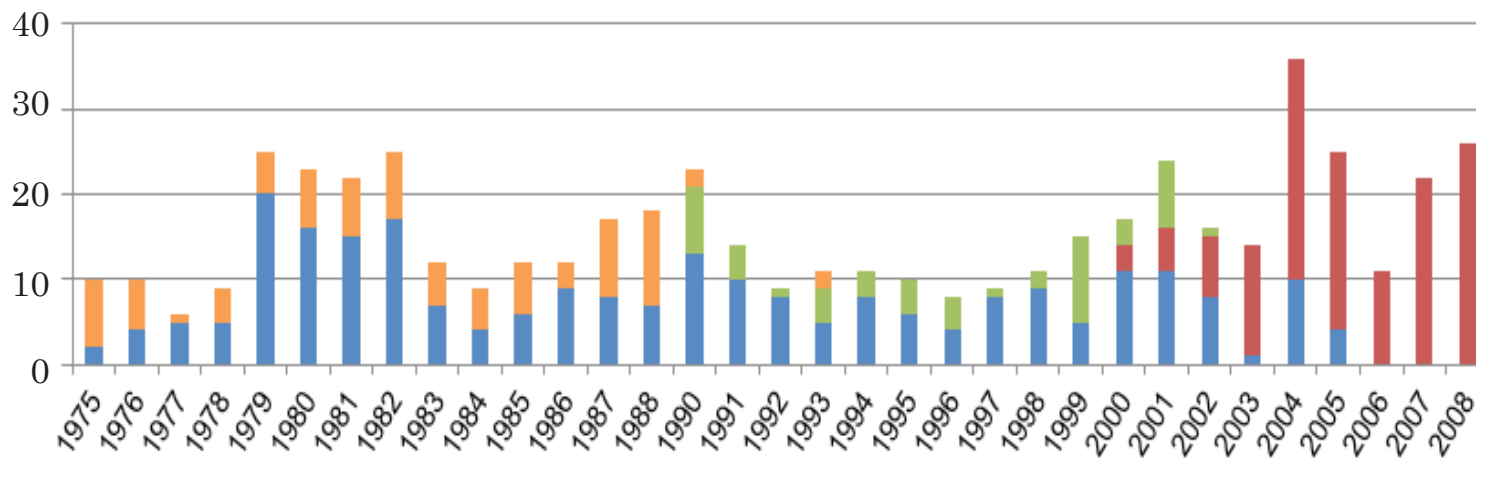

Fonte: Consulta ao INPI (2010).

As instituições depositantes foram classificadas de acordo com a natureza como empresa, indivíduos (pessoa física), institutos públicos de pesquisa e universidades. Um dado surpreendente é que apenas duas patentes foram depositadas, e posteriormente arquivadas, por uma instituição pública de pesquisa, no caso o CTA, e apenas um pedido de patente por parte de universidade, também arquivado, depositado pela Universidade de Princeton. No mais, se observam pedidos de empresas e pessoas físicas. $\mathrm{O}$ fato de apenas 
três pedidos de patente estarem relacionados com institutos de pesquisa e universidades revela o interesse da indústria nessas tecnologias e que as mesmas vêm procurando desenvolver tecnicamente os dispositivos relacionados aos motores mono e bicombustível. Os dois pedidos do CTA e revelam uma preocupação com o desenvolvimento de motores específicos a álcool.

Ao dividir os pedidos de patente por país das instituições depositantes, tem-se o seguinte quadro: o Brasil conta com 155 pedidos, seguido por Estados Unidos (112) e Alemanha (55). A maior parte dos depósitos é de não residentes, o que se repete em relação às cartas patentes (vigentes ou extintas). Os pedidos provenientes de outros países buscam reconhecer no Brasil esforços inovativos desenvolvidos no exterior, uma vez que os direitos de propriedade têm validade apenas no país que concedeu o privilégio. Tomando-se os pedidos domésticos por Unidades da Federação da instituição depositante, São Paulo detém a maior parte dos pedidos, sendo 84 processos ou 54\% da base montada. Em seguida aparece Minas Gerais, com 21 processos, e o Rio de Janeiro, com 17. É importante frisar que nos dois primeiros estados há uma grande concentração de empresas do ramo automotivo.

Após a montagem e análise da base de proteção da propriedade intelectual, foram selecionadas para uma análise mais aprofundada apenas as montadoras, indústrias de autopeças e instituições que, segundo indicação da literatura, estiveram diretamente ligadas ao desenvolvimento do Pró-álcool e dos veículos bicombustíveis. Bosch e Magneti Marelli são empresas que desenvolveram tecnologia para motores bicombustíveis e estão diretamente ligadas às montadoras, sendo que ambas são as instituições que mais depositaram pedidos de patente no período estudado. A constante concorrência entre as indústrias de autopeças pode explicar o número elevado de pedidos de patente destas empresas.

Segundo um documento elaborado pelo Ministério da Indústria e Comércio (MIC, 1979), as invenções tecnológicas produzidas basicamente no CTA, no seio do Pró-álcool, seriam licenciadas à Motorit, empresa que ficaria responsável pela difusão dessas tecnologias junto ao mercado. Observa-se uma patente já extinta e um pedido arquivado depositados por ela, indício de que o planejamento do PNA teria sido colocado em prática, mesmo que timidamente. Esta relação do CTA com a Motorit pode ser estudada por meio da análise de redes de colaboração e cooperação, bem como a colaboração da Bosch e da Magneti Marelli junto às montadoras, como apresentado a seguir 


\section{Os polos de concentração e as redes de colaboração na produção dos motores a álcool e bicombustíveis}

Voltando-se a análise ao estado de São Paulo, é notável a concentração das patentes junto das mesmas cidades que concentram as atividades de P\&D do setor de motores automotivos: São Paulo, São José dos Campos e Campinas (ver Figura 1 abaixo). Além de serem importantes polos de atividade econômica manufatureira, esta aglomeração tem relação com a presença de institutos públicos de pesquisa nesses municípios, de grandes universidades, como USP, Unicamp e ITA, e também a sede de importantes empresas nacionais e transnacionais do setor automotivo, como Bosch e Embraer. Vale ressaltar que um terço dos pedidos de proteção da propriedade intelectual é proveniente de pequenas empresas localizadas em cidades próximas aos três municípios centrais, como Santo André e Valinhos. Esta concentração reforça o que foi colocado por Mansfield e Lee (1996) sobre a interação do setor produtivo de alta tecnologia e complexidade com a mão de obra qualificada proveniente das grandes universidades.

Figura 1 - Distribuição dos Pedidos de Patente segundo a cidade dos depositantes no INPI, 2010

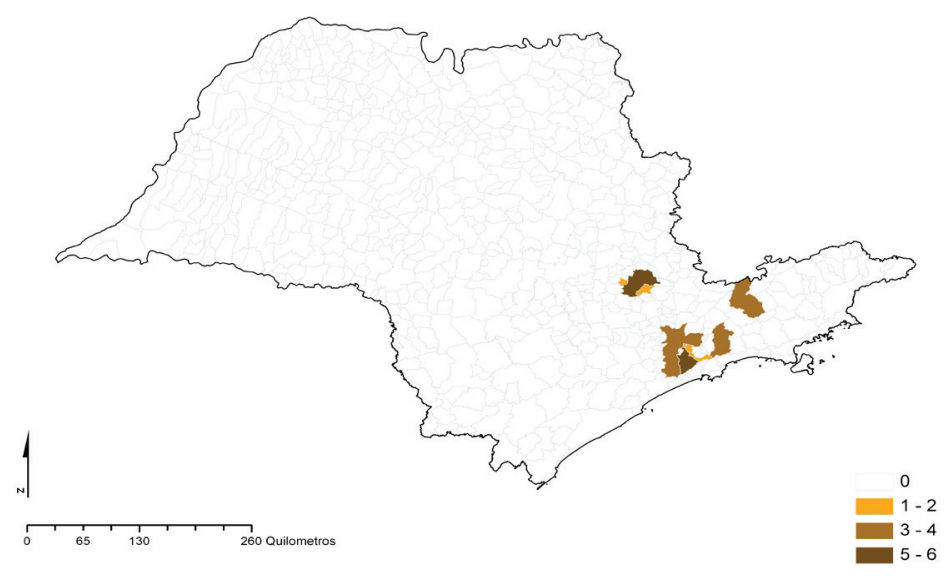

Fonte: Consulta ao INPI (2010).

No que toca à distribuição das produções científicas de instituições localizadas no estado de São Paulo na base ISI, as maiores concentrações estão ligados à presença de campi das principais universidades paulistas: USP, Unesp, Unicamp e UFSCar. Essa maior amplitude da distribuição se dá pela distribuição dos diversos campi da Unesp que possuem produções científicas (Araraquara, Bauru, Botucatu, Ilha Solteira, Guaratinguetá e São José do Rio Preto). Os artigos encontrados no Scielo apresentam-se em um número mais restrito, mas em linhas gerais estão aglomerados espacialmente em municípios como Araraquara, São Carlos, Piracicaba, Campinas e São Paulo, os quais 
podem ser considerados polos de concentração ou aglomerações da atividade científica (Figura 2).

Figura 2 - Distribuição das instituições dos pesquisadores segundo municípios dos artigos científicos encontrados nas bases ISI e Scielo
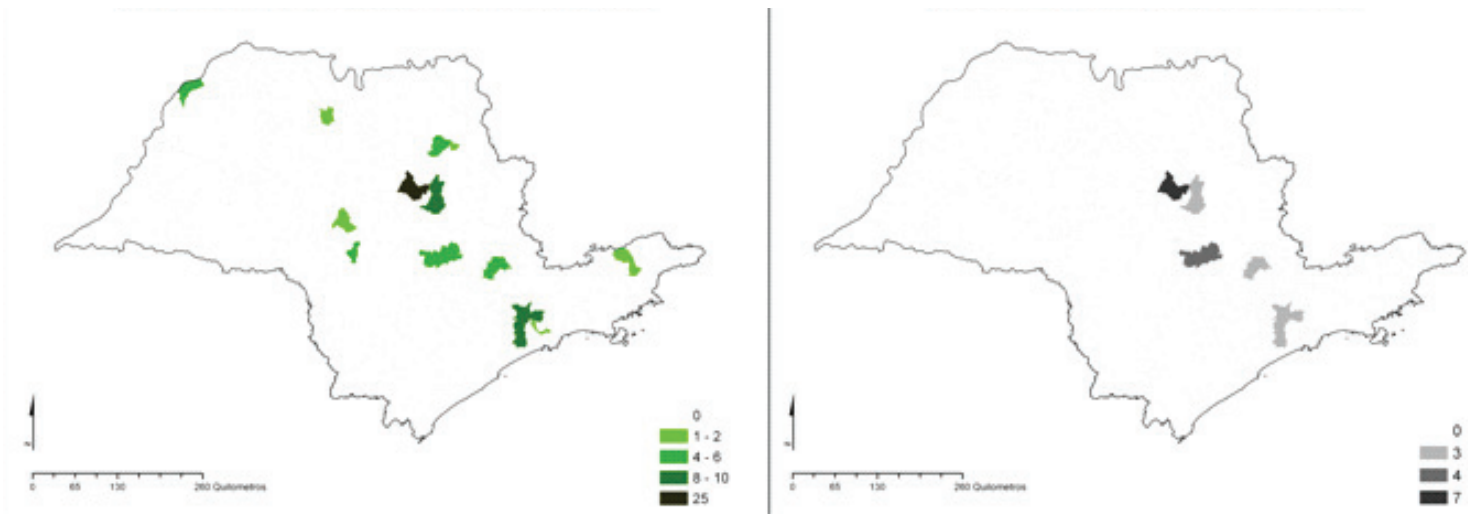

Fonte: Consulta às bases ISI - Web of Knowledge e Scielo (2010).

Segundo Dias et al. (2008), uma das formas de mensurar a formação de redes de cooperação e colaboração é a publicação em coautoria (como representado na Figura $3^{1}$ ).

Figura 3 - Rede de coautorias nos artigos encontrados na base, 1975-2009

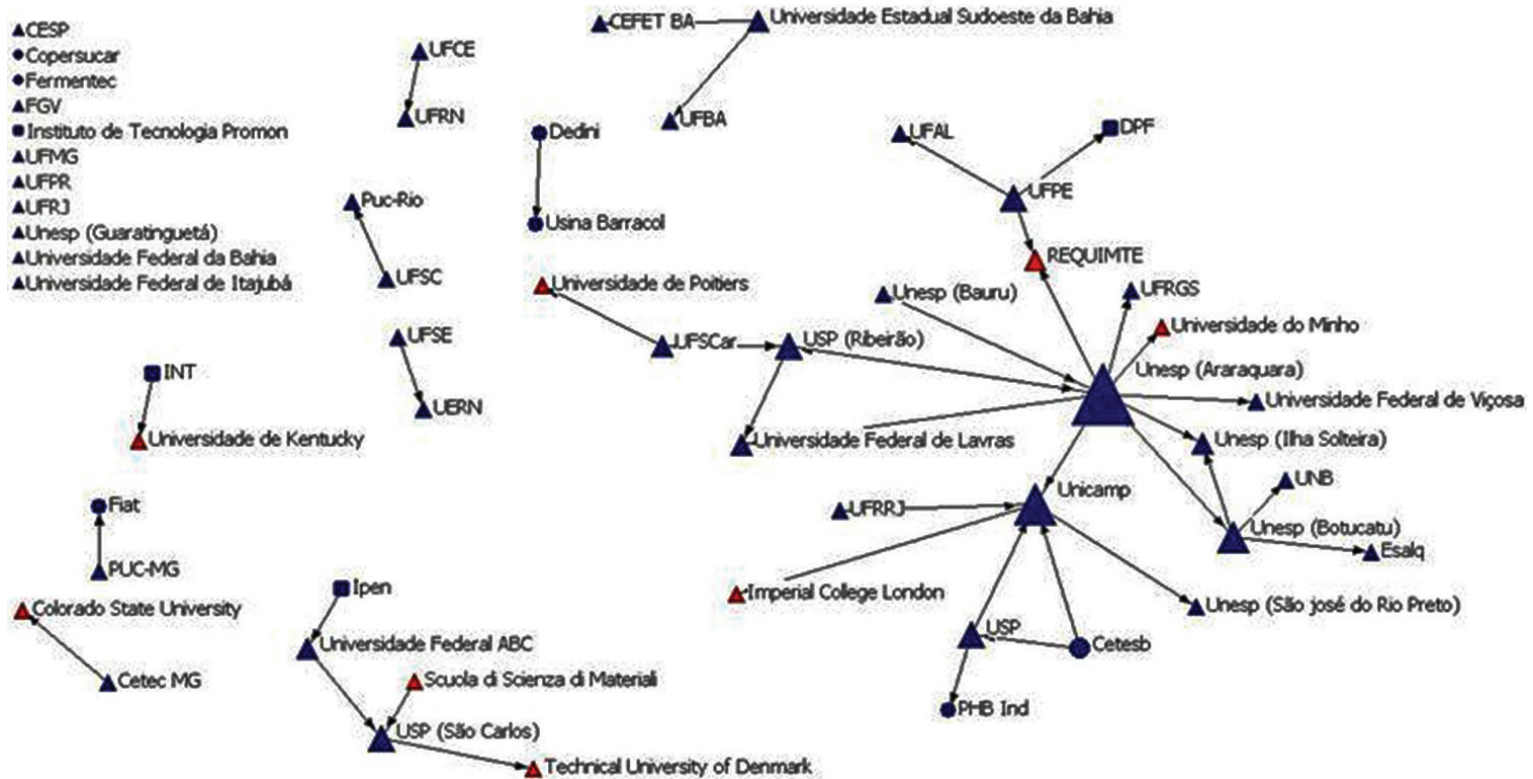

Fonte: Elaboração própria a partir de consulta à base ISI - Web of Knowledge (2010).

Os círculos representam empresas, os triângulos universidades e, por último, os quadrados os institutos de pesquisa. As formas em azul indicam que são instituições nacionais e em vermelho as internacionais. O tamanho de

1 A figura foi construída utilizando-se o software de análise de redes sociais denominado UCINET. A posição das instituições foi obtida a partir da ordenação Nodelist (1-mode). 
cada forma revela o número de artigos em parceira. Portanto, quanto maior o tamanho da forma, maior o número de contatos estabelecidos. A partir do ordenamento da figura é possível perceber a centralidade de duas instituições na maior rede formada: Unesp de Araraquara e Unicamp.

Para a análise desta rede, há, então, ao menos três tipos de atores: as instituições de pesquisa (CTA e Unicamp), uma empresa de autopeças (a Motorit) com o papel de ponte com o mercado, e por fim, as montadoras (Fiat, Volkswagen, General Motors e Ford). Isto ilustra o ciclo montado ao redor da criação do motor a álcool. A comunicação realizou-se via patentes e possibilitou a circulação das mercadorias correlatas - pistões, válvulas, anéis, carburadores, velas de ignição - todos projetados e fabricados especificamente para o funcionamento com álcool combustível.

Depois de mais de vinte anos do início do Pró-álcool e com a tecnologia dos motores a álcool complementando-se com a eletrônica e informática, Bosch e Magneti Marelli são as empresas que mais solicitaram pedidos de patente junto ao INPI. Entretanto, aparentemente não há relação direta de colaboração entre o CTA e essas empresas. Por outro lado, a interação entre universidade e centros de pesquisa com as empresas pode ser vista pelos exemplos: a Fiat Powertrain (MG), tem três artigos publicados junto com a PUC-MG (uso de biocombustíveis no Brasil); a PHB Industrial, ligada a usinas sucroalcooleiras na região de Ribeirão Preto, com publicação com USP e Unicamp (emissão de poluentes com a queima de etanol); idem quanto à Cetesb, que também publicou junto com estas duas instituições.

\section{Considerações finais}

Após o levantamento e a análise de informações sobre redes de cooperação e polos de concentração, no caso da produção científica, as redes científicas voltadas para o desenvolvimento dos motores a álcool e flex são fortemente concentradas em poucas instituições de pesquisa e ensino e em termos geográficos. Os atores centrais são as instituições mais conhecidas na área de ciência e tecnologia (USP, Unicamp e Unesp). A pequena descentralização observada se dá por conta dos campi da Unesp (espalhados pelo estado de São Paulo). Além disso, as redes formadas não são muito extensas, ou seja, não envolvem muitos atores. É importante notar também que vários atores que trabalham com o tema não formam redes.

No caso da análise de redes a partir da produção tecnológica (patentes e outros), há um número maior de atores privados (como seria mesmo esperado) e há uma forte concentração em poucas localidades geográficas no estado de São Paulo (basicamente São Paulo, Campinas e São José dos Campos). 
Entretanto o quadro resultante das análises feitas aqui é crítico, pois os números absolutos de publicações e de patentes são baixos, e também o de colaborações e cooperação. Esse contexto, de baixo dinamismo técnico-científico, se torna ainda mais grave se se consideram que os elementos centrais da análise, as áreas do conhecimento relacionadas (ciências agrárias, biologia, química, entre as mais importantes), os setores da atividade econômica (agroindústria da cana-de-açúcar e do etanol e indústria automobilística) e o estado da Federação (São Paulo), são de grande relevância para o cenário econômico, social, de C\&T e inovação nacional, pois dizem respeito a uma tecnologia sobre a qual o país tem destaque no cenário internacional. É importante apontar que o país pode estar perdendo as vantagens de ter sido pioneiro no desenvolvimento de motores a álcool e bicombustíveis, principalmente se se considera que esta perda de competitividade do país se dá em uma atividade importante economicamente e que responde a outros desafios mundialmente colocados, como o ambiental. Faz-se necessário um novo salto técnico-científico e também inovativo pra que não se perca a posição de líder neste segmento.

\section{Referências}

Dias, E. L. (2008). "A dinâmica da pesquisa em redes: avanços e desafios do seqüenciamento genético da vassoura de bruxa e do eucalipto”. Liinc em Revista 4(1): $120-137$.

INPI - Instituto Nacional da Propriedade Industrial. (2012). URL [on-line]: http://inpi. gov.br.

ISI - Web of Knowledge. (2012). URL [on-line]: http://webofknowledge.com. Acesso em: junho de 2012.

Mansfield, E.; Lee, J. (1996). "The modern university: contributor to industrial innovation and recipient of industrial R \& D support". Research Policy 25: 1047 1058.

Ministério da Indústria e do Comércio. (1979). O desempenho da Secretaria de Tecnologia Industrial, período 1974-1978 - Programa tecnológico industrial de alternativas energéticas de origem vegetal: programa tecnológico do etanol. Brasília: MIC.

Scielo - Scientific Electronic Library Online. (2012). URL [on-line]: http://scielo.org. Acesso em: junho de 2012.

Silva, A. M. A. C.; Zackiewicks, M.; Bonacelli, M. B. M. (2005). "Indicadores para monitoramento de ciência e tecnologia e apoio à decisão". XI Seminário LatinoIberoamericano de Gestión Tecnológica - ALTEC 2005 vol. 1: 1-16. 
